\title{
TELEPRACTICE IN THE ASSESSMENT AND TREATMENT OF INDIVIDUALS WITH APHASIA: A SYSTEMATIC REVIEW
}

\author{
Nerissa Hall, PhD, CCC-SLP, ${ }^{1}$ MiChelle BOISvert, PhD, CCC-SLP, ${ }^{1}$ \\ RICHARD STEELE, PHD ${ }^{2}$ \\ ${ }^{1}$ UNIVERSITY OF MASSACHUSETTS, AMHERST, MA \\ 2 LINGRAPHICA, PRINCETON, NJ
}

\section{ABSTRACT}

Telepractice involves the application of technology to deliver services over a geographical distance. Studies in which telepractice procedures were used in the assessment or treatment of individuals with aphasia were reviewed. Systematic searches identified 10 studies meeting inclusion criteria. These studies were evaluated in terms of the: (a) characteristics of the participants, (b) technology utilized (c), services delivered via telepractice, (d) research methodology, and (e) results and conclusions of the study. Telepractice was used by speech-language pathologists and allied health professionals to assist with the delivery of services to participants with aphasia by their caretakers or clinicians. The services delivered included appraisal, diagnostic assessments, interventions, and consultation. This review suggests that telepractice is a viable method of service delivery for individuals with aphasia, however further research is warranted. Guidelines for practitioners and potential directions for future research are discussed.

Keywords: Telepractice, telemedicine, telediagnosis, telehealth, telerehabilitation, videoconferencing, distance education, aphasia

\section{INTRODUCTION}

Telerehabilitation has become a practical application of technology for the provision of a variety of professional and clinical practices. This evolution in service delivery is primarily due to advancements in technology and the mainstream use of computers, the Internet, and telecommunications. In the field of speech-language pathology, the implementation of telerehabilitation services - known as telepractice - requires careful consideration to ensure that best-practices are being implemented. The very nature of the services being delivered to individuals with communication challenges, such as an acquired aphasia, require audio and visual telecommunication technologies, as well as careful consideration of how to deliver speech and language services at a distance. Furthermore, clinicians must be trained on how best to assess disorders, arrive at diagnoses, develop treatment plans, provide intervention, supply therapeutic materials, instruct in their uses, monitor patient progress, manage required paperwork, and receive third-party reimbursement for services delivered. These factors, combined with state licensing and credentialing requirements, as well as ethical, privacy, and legal issues (Brown, 2011) have resulted in slow and often uneven advancement of telepractice within the field of speech-language pathology.
The first documented use of telepractice within the field of speech-language pathology was described using telepractice with individuals with aphasia. In these pioneering studies, the researchers used a telephone to present auditory stimuli paired with printed visual materials (Vaughn, 1976a, 1976b, 1977, 1981). Since these seminal investigations there have been a number of studies examining the efficacy of telepractice with individuals diagnosed with acquired aphasia. In an effort to understand the evolution of telepractice with this population, this paper presents a review of the research on the use of telepractice with adults with acquired aphasia, with a focus on remote assessment and service delivery. Moreover, principles to help professionals understand the current state-of-practice will be identified to help further frame the clinical thinking about how to best implement evidence-based telepractice services for people diagnosed with aphasia. 


\section{METHODS}

\section{SEARCH PROCEDURES}

A systematic, five-step procedure used in other research of this kind (Boisvert, Lang, Andrianopoulos, \& Boscardin, 2010) was employed to identify studies for inclusion in this review. The steps were as follows: (1) computer literature searches were conducted in five electronic databases covering the field of health and human service- Education Resources Information Center (ERIC), Academic Search Premier, Cumulative Index to Nursing and Allied Health Literature (CINAHL), MEDLINE, and PsycINFO - using the terms "Aphasia," "Dysphasia," "Anomia," "Adult Neurogenic Disorder," "Acquired Language Disorder," "Broca's Aphasia," "Wernicke's Aphasia," "Primary Progressive Aphasia," and "Global Aphasia," paired with "Telediagnostic," "Telemedicine," "Telepractice," "Teleconference," "Skype" (), "iChat" ( ), "Videoconferencing," "Distance Education," "Telehealth," "Teletherapy," and "Telerehabilitation" (e.g., Aphasia AND Videoconferencing); (2) abstracts of identified articles were reviewed to determine compliance with the inclusion criteria specified below; (3) reference lists of studies meeting these criteria were then reviewed to identify additional articles for inclusion; (4) the surname of the first author of each of the included studies was then searched to identify additional work by that author to be considered for inclusion; and (5) hand searches of the two most recent issues of the journals that had published at least one of the included studies were conducted in order to identify recent studies that were not yet listed in the aforementioned databases.

\section{INCLUSION CRITERIA}

To be included in this review, studies had to meet predetermined inclusion criteria. The inclusion criteria for this review was as follows: (1) the study had to include at least one participant with a diagnosis of aphasia (i.e., Broca's aphasia); (2) at least one dependent variable that involved the participant with aphasia and the results of an assessment and/or the fidelity of implementation of an intervention, assessment and/or consultation; and (3) use of telepractice to deliver one of the above services from a specialist or expert at one location to a participant with aphasia at a remote location (e.g., a speech-language pathologist could conduct a language evaluation from a university clinic to an adult with aphasia in his/her home setting). In an effort to understand the evolution of telepractice for individuals with acquired aphasia, the publication year was not restricted. However, the search was limited to studies written in the English language and published in peer-reviewed journals. This literature review was conducted over the months of November and December of 2012.

\section{DATA EXTRACTION AND REVIEW PARAMETERS}

Each study was reviewed to determine whether or not it met the inclusion criteria. Then, each study was read and summarized by the first two co-authors of this review. Both co-authors hold doctoral degrees in speech and hearing science and are certified and licensed speechlanguage pathologists. The co-authors used a coding sheet designed specifically for this systematic review (available upon request) to extract data describing: (a) the characteristics of the participants with aphasia, (b) the technology utilized to support telepractice, (c) the type of services delivered via telepractice, (d) the research design utilized, and (e) the results and conclusions of the study. Various procedural features were noted, including the settings of the telepractice services and any reported advantages and disadvantages to implementation.

\section{INTER-CODER AGREEMENT}

Each co-author independently completed the literature review. The accuracy of each summary was independently checked to ensure adherence to the above listed review parameters; specifically whether or not the summary included an accurate description of the participants, technology, services delivered, research design, results and conclusions. This helped guarantee accuracy of each of the study summaries and provided a measure of intercoder agreement on data extraction and analysis. The point-by-point inter-coder agreement was calculated by dividing the number of agreements by the total number of agreements and disagreements and multiplying by 100 . Agreement for this literature review was $90 \%$.

\section{RESULTS}

To ensure the fidelity of the literature search each component of the above mentioned five-step procedure was completed independently by the co-authors. The first stage (the electronic database review of terminology combinations) yielded 26 studies. The abstracts of the 26 studies were reviewed to determine whether or not they met the inclusion criteria. Careful review of all 26 abstracts resulted in exclusion of 16 articles and therefore narrowed the selection to 10 articles. Inter-coder agreement as to whether a study should be included or excluded was $90 \%$ (i.e., agreement was obtained on 9 of the 10 studies). A study completed by Hoffman, Worrall, Eames, and Ryan (2010) was identified for inclusion by one co-author and not the other. After discussion, this study was included as service delivery via the telephone, and completion of outcome questionnaires, were considered relevant and a form of telepractice. 
Table 1 offers a summary of: (a) the participants; (b) the technology used; (c) the services delivered via telepractice; (d) the research design, and (e) the results of each of the 10 included studies. Please refer to

Table 1: Summary of Studies Included in Review Appendices A through $E$ for definitions and descriptions of specific terminology related to telepractice, types of aphasia, research designs, tests and interventions.

\begin{tabular}{|c|c|c|c|c|}
\hline Citation & Participant/s & Technology Used & Service Rendered & $\begin{array}{l}\text { Research Design } \\
\text { \&Outcome }\end{array}$ \\
\hline $\begin{array}{l}\text { Fitch, J. L. } \\
\text { (1983). }\end{array}$ & $\begin{array}{l}1 \text { participant: } \\
54 \text { year-old woman, } \\
\text { global aphasia and } \\
\text { apraxia }\end{array}$ & $\begin{array}{l}\text { PDP 11/44 } \\
\text { minicomputer at the VA } \\
\text { Medical Center in } \\
\text { Birmingham \& } \\
\text { Touchtone telephone } \\
\text { for response recording. }\end{array}$ & $\begin{array}{l}\text { Auditory } \\
\text { comprehension } \\
\text { intervention involving } \\
\text { response plates } \\
\text { containing } 4 \text { possible } \\
\text { options. }\end{array}$ & $\begin{array}{l}\text { Research Design: } \\
\text { Single-subject case } \\
\text { study. } \\
\text { Results: Completion } \\
\text { interventions revealed } \\
\text { that service delivery via } \\
\text { telecomputer was } \\
\text { feasible }\end{array}$ \\
\hline $\begin{array}{l}\text { Georgeadis, A. C., } \\
\text { Brenna, D. M., } \\
\text { Barker, L. M.,\& } \\
\text { Baron, C. R. } \\
\text { (2004). }\end{array}$ & $\begin{array}{l}40 \text { participants: } \\
\text { all diagnosed with } \\
\text { recent brain injury } \\
-12 \text { TBI, } 14 \text { LCVA, } \\
14 \text { RCVA }\end{array}$ & $\begin{array}{l}\text { Flat panel computer } \\
\text { monitor using } \\
\text { computer-based } \\
\text { videoconferencing with } \\
\text { full-duplex audio and } \\
\text { video. Internet } \\
\text { connection utilized } \\
\text { high bandwidth (10 } \\
\text { Mbps) Local Area } \\
\text { Network }\end{array}$ & $\begin{array}{l}\text { Completion of a } \\
\text { standardized SLP } \\
\text { assessment - Story } \\
\text { Retell Procedure - in } \\
\text { both in-person and } \\
\text { telepractice settings. } \\
\text { Participants were also } \\
\text { asked to complete a } \\
\text { satisfaction survey. }\end{array}$ & $\begin{array}{l}\text { Research Design: } \\
\text { Alternative Treatment } \\
\text { Design } \\
\text { Results: No significant } \\
\text { difference between } \\
\text { telepractice \& } \\
\text { in-person services. } \\
\text { Satisfaction surveys } \\
\text { revealed high } \\
\text { acceptance of } \\
\text { telepractice. } \\
\text { Researchers } \\
\text { determined that story } \\
\text { telling is not affected } \\
\text { by setting. }\end{array}$ \\
\hline $\begin{array}{l}\text { Goldberg, S., } \\
\text { Haley, K. L., \& } \\
\text { Jacks, A. } \\
\text { (2012). }\end{array}$ & $\begin{array}{l}2 \text { participants: } \\
\text { Aphasia }\end{array}$ & Videoconferencing. & $\begin{array}{l}\text { Each participant was } \\
\text { trained on } 2 \text { relevant } \\
\text { scripts, and } \\
\text { participated in } \\
\text { intervention } 3 x / \text { week } \\
\text { with a combination of } \\
\text { in-person meetings } \\
\text { and videoconferencing. }\end{array}$ & $\begin{array}{l}\text { Research Design: } \\
\text { Multiple-baseline } \\
\text { across scripts } \\
\\
\text { Results: Both } \\
\text { participants showed } \\
\text { improvement. } \\
\text { Researchers } \\
\text { concluded that } \\
\text { videoconferencing is a } \\
\text { viable method of } \\
\text { conducting script } \\
\text { training. }\end{array}$ \\
\hline $\begin{array}{l}\text { Helm-Estabrooks, N., } \\
\text { \& Ramsberger, G. } \\
\text { (1986). }\end{array}$ & $\begin{array}{l}1 \text { participant: } \\
\text { non-fluent aphasia, } \\
11 \text { years post-onset }\end{array}$ & $\begin{array}{l}\text { Telephone delivery } \\
\text { of speech-language } \\
\text { programs. }\end{array}$ & $\begin{array}{l}\text { Hierarchically } \\
\text { structured syntax } \\
\text { treatment program, } \\
\text { with pre-/post-treatment } \\
\text { performance measures } \\
\text { on the Northwestern } \\
\text { Syntax Screening Test, } \\
\text { Boston Diagnostic } \\
\text { Aphasia Examination } \\
\text { (BDAE) }\end{array}$ & $\begin{array}{l}\text { Research Design: } \\
\text { Single-subject, AB } \\
\text { design, pre-/post- } \\
\text { Results: Improvement } \\
\text { noted with both } \\
\text { performance measures }\end{array}$ \\
\hline $\begin{array}{l}\text { Hill, A., } \\
\text { Theodoros, D. G., } \\
\text { Russell, T. G., } \\
\text { Ward, E. C., } \\
\text { Wootton, R. } \\
\text { (2009). }\end{array}$ & $\begin{array}{l}32 \text { participants: } \\
\text { acquired aphasia }\end{array}$ & $\begin{array}{l}\text { Two computers with } \\
\text { custom-built software } \\
(640 \times 480 \text { pixels } \\
\text { resolution) and } \\
\text { Logitech Pro } 4000 \\
\text { webcams. Use of a } \\
128 \text { kbit/s Internet } \\
\text { connection. }\end{array}$ & $\begin{array}{l}\text { Simultaneous } \\
\text { assessment (via } \\
\text { telepractice and } \\
\text { in-person) using the } \\
\text { Boston Diagnostic } \\
\text { Aphasia Examination } \\
\text { (BDAE) and the Boston } \\
\text { Naming Test (BNT). }\end{array}$ & $\begin{array}{l}\text { Research Design: } \\
\text { AB/simultaneous } \\
\text { recording } \\
\text { Results: Severity of } \\
\text { aphasia did not } \\
\text { influence the accuracy } \\
\text { of telepractice } \\
\text { assessment, except on } \\
\text { the ability to assess } \\
\text { naming and paraphasias. }\end{array}$ \\
\hline
\end{tabular}




\begin{tabular}{|c|c|c|c|c|}
\hline Citation & Participant/s & Technology Used & Service Rendered & $\begin{array}{l}\text { Research Design } \\
\text { \&Outcome }\end{array}$ \\
\hline $\begin{array}{l}\text { Hoffman, T., } \\
\text { Worrall, L., } \\
\text { Eames, S., \& } \\
\text { Ryan, A. } \\
\text { (2010). }\end{array}$ & $\begin{array}{l}19 \text { participants: } \\
11 \text { with aphasia, } \\
\text { and } 8 \text { caregivers. }\end{array}$ & $\begin{array}{l}\text { Telephone } \\
\text { administration of } \\
\text { stroke outcome } \\
\text { measures. }\end{array}$ & $\begin{array}{l}\text { Participants were } \\
\text { randomized to receive } \\
\text { telephone or in-person } \\
\text { administration of 1st or } \\
\text { 2-week follow-up. }\end{array}$ & $\begin{array}{l}\text { Research Design: } \\
\text { Randomized } \\
\text { Controlled Trial (RCT) } \\
\text { Results: No significant } \\
\text { difference between } \\
\text { scores obtained }\end{array}$ \\
\hline $\begin{array}{l}\text { Lasker, J. P., } \\
\text { Stierwalt, A. G., } \\
\text { Spence, M., \& } \\
\text { Calvin-Root, C. } \\
\text { (2010). }\end{array}$ & $\begin{array}{l}1 \text { participant: } 28 \\
\text { year-old, apraxia and } \\
\text { aphasia }\end{array}$ & $\begin{array}{l}\text { Computer and headset } \\
\text { using Skype for } \\
\text { videoconferencing. } \\
\text { Retention probes were } \\
\text { recorded using Call } \\
\text { Recorder TM software. }\end{array}$ & $\begin{array}{l}4 \text { sessions per week - } \\
2 \text { in-person } \\
\text { sessions/week + } 2 \\
\text { sessions via } \\
\text { Skype/week; motor } \\
\text { learning guided (MLG) } \\
\text { and speech generating } \\
\text { device (SGD) } \\
\text { approach. }\end{array}$ & $\begin{array}{l}\text { Research Design: } \\
\text { Single-subject case } \\
\text { study. } \\
\text { Results: Similar } \\
\text { outcomes between two } \\
\text { treatments using } \\
\text { MLG/SGD approach in } \\
\text { terms of intelligibility, } \\
\text { immediacy, and } \\
\text { naturalness ratings. }\end{array}$ \\
\hline $\begin{array}{l}\text { McGrath, N., } \\
\text { Dowds, M. M., \& } \\
\text { Goldstein, R. } \\
\text { (2008). }\end{array}$ & $\begin{array}{l}1 \text { participant: } 41 \\
\text { year-old male, } \\
\text { expressive aphasia }\end{array}$ & $\begin{array}{l}\text { Video teleconferencing } \\
\text { (VTC) for weekly } \\
\text { meetings. }\end{array}$ & $\begin{array}{l}\text { Weekly meetings } \\
\text { during implementation } \\
\text { of a community } \\
\text { reintegration program. }\end{array}$ & $\begin{array}{l}\text { Research Design: } \\
\text { 3-month, A-B-A } \\
\text { design, weekly VTC } \\
\text { meetings (substituted } \\
\text { for in-person meetings) } \\
\text { Results: Client and } \\
\text { case coordinator found } \\
\text { VTC meetings to be as } \\
\text { effective as in-person } \\
\text { supervision visits. }\end{array}$ \\
\hline $\begin{array}{l}\text { Palsbo, S. E. } \\
\text { (2007). }\end{array}$ & $\begin{array}{l}24 \text { participants: } \\
\text { post-stroke patients } \\
\text { with aphasia }\end{array}$ & $\begin{array}{l}\text { Videoconferencing } \\
\text { operated at a } \\
\text { transmission speed of } \\
384 \mathrm{kbit} / \mathrm{s} \text { ) }\end{array}$ & $\begin{array}{l}\text { Simultaneous } \\
\text { assessment (via } \\
\text { telepractice and } \\
\text { in-person) using the } \\
\text { Boston Diagnostic } \\
\text { Aphasia Examination } \\
\text { (BDAE). }\end{array}$ & $\begin{array}{l}\text { Research Design: } \\
\text { Randomized, } \\
\text { double-crossover } \\
\text { agreement study } \\
\text { Results: 95\% } \\
\text { agreement for each } \\
\text { functional } \\
\text { communication } \\
\text { measure regardless of } \\
\text { assessment site. } \\
\text { Results indicate that } \\
\text { videoconferencing is } \\
\text { equivalent to in-person } \\
\text { service delivery. }\end{array}$ \\
\hline $\begin{array}{l}\text { Theodoros, D., } \\
\text { Hill, A., } \\
\text { Russell, T., } \\
\text { Ward, E., \& } \\
\text { Wootton, R. } \\
\text { (2008). }\end{array}$ & $\begin{array}{l}32 \text { participants: } \\
\text { aphasia from } \\
\text { stroke/TBI }\end{array}$ & $\begin{array}{l}\text { Internet-based } \\
\text { videoconferencing } \\
\text { system using a } \\
\text { bandwidth of } 128 \\
\text { Kbit/s). }\end{array}$ & $\begin{array}{l}\text { Simultaneous } \\
\text { assessment (via } \\
\text { telepractice and } \\
\text { in-person) using the } \\
\text { Boston Diagnostic } \\
\text { Aphasia Examination } \\
\text { (BDAE), the Boston } \\
\text { Naming Test (BNT), } \\
\text { and satisfaction } \\
\text { survey. }\end{array}$ & $\begin{array}{l}\text { Research Design: } \\
\text { Alternative Treatment } \\
\\
\text { Results: High } \\
\text { participant satisfaction. } \\
\text { Researchers } \\
\text { concluded that } \\
\text { telepractice can be an } \\
\text { effective rehabilitation } \\
\text { tool. }\end{array}$ \\
\hline
\end{tabular}




\section{PARTICIPANT CHARACTERISTICS}

Collectively, the 10 studies involved a total of 153 participants. The sample size of individual studies ranged from one (1) to forty (40) participants. The studies assessed the outcome of an intervention and/or the comparison of assessment results when services were delivered in-person as compared to telepractice. Four studies included only one participant (Fitch, 1983; HelmEstabrooks \& Ramsberger, 1986; Lasker, Stierwalt, Spence, \& Calvin-Root, 2010; McGrath, Dowds, \& Goldstein, 2008). One study involved two participants (Goldberg, Haley, \& Jacks, 2012), one study included 19 participants (Hoffman, Worrall, Eames, \& Ryan, 2010), and one study provided services to 24 participants. Two studies included 32 participants (Hill, Theodoros, Russell, Ward, \& Wootton, 2009; Theodoros, Hill, Russell, Ward, \& Wootton, 2008), and the final study included 40 individuals (Georgeadis, Brenna, Barker, \& Baron, 2004).

The 10 studies involved eight caregivers (Hoffman et al., 2010). A reported 77 (50\%) of participants were males and $51(33 \%)$ were females. The gender of the remaining 25 participants was not reported. Of the 10 studies, nine reported specific information regarding diagnoses of the participants (all but Palsbo, 2007) and yielded inclusion of 92 individuals $(60 \%)$ with a diagnosis of aphasia. Of these 92 individuals with aphasia, $75(81 \%)$ were diagnosed as having mild-severe aphasia, 13 (14\%) as having nonfluent/Broca's aphasia, one (1\%) as having expressive aphasia, one (1\%) as having fluent aphasia, one (1\%) as having conduction aphasia, and one (1\%) participant as having a combined expressive and receptive aphasia. Furthermore, it was reported that 13 of the 92 individuals diagnosed with aphasia (14\%) had a concomitant apraxia of speech.

\section{TECHNOLOGY USED}

The 10 included studies utilized a variety of technological supports ranging from telephones and widely available equipment to highly-customized and exclusive tools (please reference Appendix A). Two studies used telephones (Helm-Estabrooks \& Ramsberger, 1986; Hoffman, 2010), five used videoconferencing/ video teleconferencing/Skype (C) (Georgeadis et al., 2004; Goldberg, 2012; Lasker et al., 2010; McGrath et al., 2008; Palsbo, 2007), two used a custom-built videoconferencing system developed at the University of Queensland (Hill et al., 2009; Theodoros et al., 2008), and one study used a PDP 11/44 minicomputer and LSI 11/23 microcomputer system used at the Veterans Administration Medical Center (Fitch, 1983).

Of those studies using videoconferencing, Georgeadis and colleagues (2004) reported using a high bandwidth (10 Mbps) Local Area Network connection to transmit audio and video information via the Internet. Palsbo
(2007) used a connection transmitting information at 384 $\mathrm{kbits} / \mathrm{sec}$, and the custom-built University of Queensland system used in the Hill et al., 2009, and Theodoros et al., 2008, investigations shared data at $128 \mathrm{kbits} / \mathrm{sec}$.

\section{SERVICES DELIVERED}

A variety of services were delivered via telepractice. Four of the studies used telepractice for assessment purposes (Hill et al., 2009; Georgeadis et al., 2004; Palsbo, 2007; Theodoros et al., 2008), and one used the telephone to administer stroke outcome questionnaires (Hoffman et al., 2010). Four studies employed telepractice for a range of intervention services including services designed to increase auditory comprehension (Fitch, 1983), provide practice of individualized scripts (Goldberg et al., 2012), target syntax (Helm-Estabrooks \& Ramsberger, 1986), and work on specific verbal targets (Lasker et al., 2010). Lastly, McGrath and colleagues (2008) used video teleconferencing to conduct weekly consultation meetings with an individual participating in a community reintegration program.

\section{RESEARCH DESIGNS}

The most common research design used to evaluate the efficacy of assessment, intervention, and consultation services delivered via telepractice was a single-subject experimental design. This type of research design was implemented for $60 \%$ of the studies. Fitch (1983), Helm-Estabrooks and Ramsberger (1986), as well as Lasker and colleagues (2010) described using a singlesubject $A B$ (i.e., pre-/post-treatment) case study to detail implementation of specific interventions for individuals with aphasia. Georgeadis et al., (2004), Hill et al., (2009), and Theodoros et al., (2008) used variations of this design to compare the feasibility and effectiveness of assessments conducted in traditional (i.e., in-person) and telepractice conditions (i.e. alternative treatment). A multiple baseline research study was used in $20 \%$ of the presented studies. Goldberg et al. (2012) and McGrath et al. (2008) exerted more experimental control and employed multiple-baseline and ABA experimental designs to measure the effectiveness of interventions. A randomized double cross-over design was implemented in $10 \%$ of the studies. Palsbo (2007) used this method to compare telepractice to traditional, in-person assessment procedures. The remaining study ( $10 \%$ of selected investigations) implemented informal observations to gather qualitative information regarding the telepractice services provided (Fitch, 1983). It is important to note that four of the studies included in this review used satisfaction surveys (Georgeadis et al., 2004; Hill et al., 2009; McGrath et al., 2008; Theodoros, 2008). 


\section{OUTCOMES}

All ten of the investigations included in this review confirmed the feasibility of telepractice for the implementation of diagnostic, intervention, and consultative services for individuals with aphasia. Of those studies that examined the effectiveness of assessments conducted in-person and via telepractice (Georgeadis et al., 2004; Palsbo, 2007; Theodoros et al., 2008), all reported no significant differences between assessment scores and results obtained in each therapeutic environment. Hill and colleagues (2009) investigated assessments conducted via telepractice and in traditional settings, and focused on the effect of aphasia severity on clinicians' ability to administer language assessment protocols. This team concluded that the "severity of aphasia did not greatly influence the accuracy of telerehabilitation assessment...[but] severity of aphasia appeared to affect the ability to assess naming and paraphasias" (p. 627).

The studies that used the telephone and/or videoconferencing tools to provide intervention and consultation services found that services conducted via telepractice were feasible and equally as effective when compared to in-person interventions (as evidenced by dependent variable measures). Overall, the studies included in this review found that telepractice is an effective tool for service delivery for individuals with aphasia.

\section{DISCUSSION}

The evidence gathered from the studies included in this review suggests that assessment, intervention, and consultative services conducted via telepractice are feasible, effective, and equivalent to in-person services for individuals with aphasia. Further review of the included studies yielded some advantages and disadvantages to telepractice services. Advantages discussed were as follows: (1) participants' improved attentiveness to stimuli and materials presented via computers (Fitch, 1983), (2) reduced cost of travel (Fitch, 1983; Lasker et al., 2010; McGrath et al., 2008), (3) decreased cost of treatment (Fitch, 1983; Goldberg et al., 2012), (4) more effective use of time (Goldberg et al., 2012; Hoffman et al., 2010; McGrath et al., 2008); (5) successful delivery of services to those who would otherwise be unable to receive services due to geographical locale (Helm-Estabrooks \& Ransberger, 1986); and (6) improved attendance and adherence to intervention protocols (Hoffman et al., 2010; Lasker et al., 2010; McGrath et al., 2008).

The authors of the studies discussed some limitations and challenges to telepractice services that are important to consider. Limitations and disadvantages were as follows: (1) difficulty sustaining telephone and/or Internet connections (Fitch, 1983), (2) challenges communicating over a distance due to connectivity and a resulting audio/ video delay (Georgeadis et al., 2004; Goldberg et al., 2012; Lasker et al., 2010; McGrath et al., 2008; Theodoros et al., 2008); (3) reduced quality of visual cues and stimuli than that available in traditional settings (Goldberg et al., 2012); and (4) client concerns regarding privacy and equipment (McGrath et al., 2008).

The disadvantages listed above are by no means insurmountable. Each of the above listed challenges was related to the technology used to support and deliver the services. The continuously evolving and advancing resource of widely available technology will help counteract challenges associated with connectivity, transmission speed, and audio/video quality. Hill and colleagues (2009) advise, "difficulties such as audio and video quality deterioration may be eliminated with the use of higher bandwidths" (p. 639). Upload/download Internet speeds (related to the broadband connectivity) greatly impact the overall quality of telepractice services that can be provided. In the studies that reported the actual bandwidth speed, Georgeadis and colleagues (2004) successfully provided telepractice services using a $10 \mathrm{Mbps}$ bandwidth Local Area Network connection. Palsbo (2007) used a $384 \mathrm{kbits} / \mathrm{sec}$, Hill et al., (2009) and Theodoros et al., (2008) used 128 kbits/ sec to provide telepractice services with a high level of fidelity. Interestingly, in the US, the average broadband connection speed is approximately 6.6 Mbps (Akamai, 2012) which, based upon the results of these studies, would support the use of telepractice with a high level of quality.

In addition to having access to an adequate Internet connection, other more advanced off-the-shelf technology equipment will ensure the integrity of telepractice services. For example, wired Internet connections established through standard Ethernet cables offer more reliable Internet connections. Hands-free echocancellation microphones (Georgeadis et al., 2004) and high definition, external webcams will improve the quality of audio and video data shared between different locations. In a recent publication, Boisvert, Hall, Andrianopoulos, and Chaclas (2012) describe the hardware, software, and Internet requirements needed to implement high quality, evidence-based telepractice services - all of which are widely available to the general public and are not restricted to clinical and/or university institutions.

\section{FUTURE RESEARCH}

The studies included in this literature review highlight the sheer paucity of investigations in the use of telepractice with individuals with aphasia. It is critically important that researchers continue to examine the effectiveness of services for individuals with aphasia using more robust research designs such as randomized 
investigations and use of control groups. Implementation of better-controlled designs would enable researchers to compare performance and outcome data of services rendered via telepractice as compared to in-person services.

Replication of the assessments, interventions, and procedures cited in this review is necessary to further generalize the use and application of telepractice for this population. In addition, a greater range of assessment and intervention services (i.e., functional gains therapy) delivered via telepractice should be examined. Further exploration is warranted to determine the amount of support needed and rate of learning demonstrated with a range of technology, equipment, and software by individuals with aphasia. This information is critical to identifying the specific intervention and training needs of this population in order to adequately implement a telepractice service delivery model.

Furthermore, researchers should continue to explore issues of reimbursement (including Medicare and private insurance companies), HIPAA and privacy, procedures and policies (i.e., encryption, firewalls, passwords, etc.), as well as the ethical considerations necessary to better serve individuals with aphasia.

\section{CONCLUSION}

The outcome of this review suggests that telepractice is an effective way to deliver services to individuals with aphasia. The findings indicated that telepractice is a viable form of service delivery that can enhance the quality of services by making assessments, interventions and consultation available to individuals in geographically remote areas, reducing scheduling conflicts and travel time, and maximizing the utility of material resources.

Given the advancements of technology and the growing need for speech and language services, it is anticipated that telepractice will be an accepted form of service delivery in the future. Telepractice has the potential to extend clinical outreach and provide services to patients and clients diagnosed with aphasia who may have physical mobility limitations. As hardware, software, and other associated technology for clinical purposes become more widely used, the integration of this methodology will support clinical telepractice services for individuals with aphasia.

This systematic review clearly depicts the range of telepractice services and the advancement of these services for individuals with aphasia. The investigations completed by researchers and teams included in this review provide foundational evidence that can help refine the quality of services for individuals with aphasia. This information, in combination with the advancements in technology, supplementary equipment, and infrastructure of the Internet will ultimately enhance the quality, quantity, and accessibility of services for individuals with aphasia.

\section{REFERENCES}

1. Akamai Technologies, Inc. (2012). The state of the Internet: 2nd quarter, 2012 report. Available from http:// www.akamai.com/stateoftheinternet/

2. ASHA - American Speech-Language-Hearing Association. (2009). Telepractice for SLPs and Audiologists. Available from http://www.asha.org/ practice/telepractice/

3. ASHA - American Speech-Language-Hearing Association. (2005a). Knowledge and skills needed by speech-language pathologists providing clinical services via telepractice [Knowledge and Skills]. Available from http://www.asha.org/policy doi: 10.1044/policy.KS200500077

4. ASHA - American Speech-Language-Hearing Association. (2005b). Speech-language pathologists providing clinical services via telepractice: Technical report [Technical Report]. Available from www.asha.org/ policy

5. Boisvert, M.K., Hall, N., Andrianopoulos, M., \& Chaclas, J. (2012). The multi-faceted implementation of telepractice to service individuals with autism. International Journal of Telerehabilitation, 4(2), 11-24.

6. Boisvert, M.K., Lang, R., Andrianopoulos, M.V., \& Boscardin, M. (2010). Telepractice in the assessment and treatment of individuals with autism spectrum disorders: A systematic review. Developmental Neurorehabilitation, 13, 423-432.

7. Brown, J. (2011). ASHA and the evolution of telepractice. Perspectives on Telepractice, 1, 4-9.

8. Fitch, J. L. (1983). Telecomputer treatment for aphasia. Journal of Speech and Hearing Disorders, 48, 335-336.

9. Georgeadis, A. C., Brenna, D. M., Barker, L. M., \& Baron, C. R. (2004). Telerehabilitation and its effect on story retelling by adults with neurogenic communication disorders. Aphasiology, 18, 639-652.

10. Goldberg, S., Haley, K. L., \& Jacks, A. (2012). Script training and generalization for people with aphasia. American Journal of Speech-Language Pathology, 21, 222-238.

11. Goodglass, H., Kaplan, E., \& Barresi, B. (2001). Boston Diagnostic Aphasia Examination (3rd ed.). Baltimore, MD: Lippincott Williams \& Wilkins.

12. Helm-Estabrooks, N., \& Ramsberger, G. (1986). Aphasia treatment delivered by telephone. Archives of Physical Medication and Rehabilitation, 67, 51-53.

13. Hill, A., Theodoros, D., Russell, T., Ward, E., \& Wootton, R. (2009). The effects of aphasia severity on the ability to assess language disorders via telerehabilitation. Aphasiology, 23, 627-642.

14. Hoffman, T., Worrall, L., Eames, S., \& Ryan, A. (2010). Measuring outcomes in people who have has a stroke in their careers: Can the telephone be used? Topics in Stroke Rehabilitation, 17, 119-127.

15. Kaplan, E., Goodglass, H., \& Weintraub, S. (2001). Boston Naming Test (2nd ed.). Baltimore, MD: Lippincott Williams \& Wilkins.

16. Kertesz, A. (1982). Western Aphasia Battery. New York, NY: Grune \& Stratton.

17. Lasker, J. P., Stierwalt, A. G., Spence, M., \& CalvinRoot, C. (2010). Using webcam interactive technology to implement treatment for severe apraxia: A case example. Journal of Medical Speech-Language Pathology, 18(4), 4-10. 
18. Maine Legislature. (2009). LD 1073, An Act to Provide for Insurance Coverage of Telemedicine Services.

19. Mashima, P. A., \& Doarn, C. R. (2008). Overview of telehealth activities in speech-language pathology. Telemedicine and e-Health, 14, 1101-1117. doi:10.1089/ tmj.2008.0080

20. Mayo Clinic Procedures for Language Evaluation. Unpublished.

21. McGrath, N., Dowds, M. M., \& Goldstein, R. (2008). Clinical supervision of a client with traumatic brain injury in a host home placement using video teleconferencing: A case study. Journal of Head Trauma Rehabilitation, 23, 388-392

22. Palsbo, S. E. (2007). Equivalence of functional communication assessment in speech pathology using videoconferencing. Journal of Telemedicine \& Telecare, 13(1), 40-43.

23. Porch, B. E. (1967). The Porch Index of Communicative Ability. Palo Alto, CA: Consulting Psychologist Press.

24. Theodoros, D., Hill, A., Russell, T., Ward, E., \& Wootton, R. (2008). Assessing acquired language disorders in adults via the Internet. Telemedicine and e-Health, 14, 552-557. doi: 10.1089/tmj.2007.0091

25. Vaughn, G. R. (1976a). Tel-communicology: Healthcare delivery system for persons with communicative disorders. ASHA, 18, 13-17.

26. Vaughn, G. R. (1976b). Innovative systems for improved and expanded delivery of health care and the exchange of medical information and medical information services for veterans with speech disorders. Final report, TelCommunicology: VAMED \#10. Veterans Administration Exchange of Medical Information Service.

27. Vaughn, G. R. (1977). Tel-communicology: Outreach services for rural Americans with communication disorders. Congressional Record-House, 11981-2.

28. Vaughn, G. R. (1981). Efficacy of remote delivery of aphasia treatment by tel-communicology. Veterans Administrations Rehabilitation Research and Development Proposal. 
Appendix A: List of Terms Related to Telepractice and Technology
Term
Definition

Bandwidth

Bit-rate within a given period, over the Internet.

Is a measurement of how fast information is processed and transferred over a communication link, like the Internet. It is measured in bits per second (bit/s), kilobits per second (kbit/s), megabits per second (Mbit/s), gigabits per second (Gbit/s), and terabits per second (Tbits/s)

Closed Circuit Television

Refers to the transmission of video camera signals to a specific and defined location (rather than an open transmission). This is often found in video surveillance systems.

\section{Ethernet}

A wired system for connecting a number of computers to a local area network (LAN).

Firewall

Flat Panel Monitor

Full-Duplex Audio

Kilobits (kbits)

Local Area Network (LAN)

LSI 11/23 Microcomputer

Megabytes Per Second (Mbps)

PDP 11/44 Minicomputer

Pixels

Remote Machine Assisted Treatment and Evaluation (REMATE) computer resource

Resolution

Skype@

TEL-Communicology

Telecomputer

Telephone with Touch Pads

Telepractice $(\mathrm{T})$

Touchtone Telephone

Video Teleconferencing/

Videoconferencing

Webcam
A hardware-based or software-based network barrier designed to filter material and keep a network safe.

A light-weight electronic visual display, also known as a flat screen, with a flat front surface.

Two-way audio that can be recorded and reproduced at the same time.

A unit of computer memory/data/storage that is equal to approximately 1,000 bits.

A computer network that connects and links computer devices within a given area (i.e., building or group of buildings).

A PDP-11 minicomputer that has a large-scale integration processor.

A unit of computer memory/data/storage that is equal to approximately $1,000,000$ bits.

Part of a series of 16-bit general purpose minicomputers sold by Digital Equipment Corporation in the late 1990's.

A miniature area of illumination on an electronic visual display. In the display, individual pixels form an image.

A computer used as part of the REMATE project at the Veteran's Administration Medical Center in Birmingham, Alabama. The computer "responds to the frequency of the tone generated when the patient presses a key (button) on the Touchtone

telephone" (Fitch, 1983, p. 47) with a maximum of 12 different possible responses correlating with the 12 keys of a Touchtone key pad.

The number of distinct pixels that are displayed in each dimension on an electronic visual display.

A software application that allows individuals to make voice and video calls over the Internet.

A system that uses a telephone to present auditory stimuli paired with printed visual materials, and a range of patient response recording techniques.

A device that combines features of a computer, television, and telephone and is able to receive and transmit audio and visual information via the Internet.

A telephone with a number/letter keypad.

The delivery of professional services over a geographical distance using telecommunications technologies.

A telephone within which calls are made by touching keys/buttons on the device that transmits varying tones/pitches.

The process of using a set of telecommunication technologies that support two-way audio and visual communication across two or more locations.

A video camera that transmits video images via the Internet.

* Information for the definitions was collected from Google and Wikipedia. 
Appendix B: Bit-rate Conversion

\begin{tabular}{|l|l|}
\hline Term & Definition \\
\hline Kilobit/second (kbit/s) & 1,000 bits \\
\hline Megabit/second (Mbit/s) & $1,000,000$ bits \\
\hline Gigabit/second (Gbit/s) & $1,000,000,000$ bits \\
\hline Terabit/second (Tbit/s) & $1,000,000,000,000$ bit \\
\hline
\end{tabular}

* Information gathered from Wikipedia.

Appendix C: Definitions and Distinctions between Types of Aphasia and Associated Diagnoses

\begin{tabular}{|c|c|}
\hline Term & Definition \\
\hline Acquired Aphasia & $\begin{array}{l}\text { Loss or impairment of expressive and/or language skills that were previously } \\
\text { possessed. }\end{array}$ \\
\hline Anomia & Significant difficulty recalling words and/or names. \\
\hline Aphasia & $\begin{array}{l}\text { A communication disorder resulting from damage to parts of the brain devoted to } \\
\text { speech and language. }\end{array}$ \\
\hline Apraxia & $\begin{array}{l}\text { A neurological speech sound disorder characterized by difficulty with articulatory } \\
\text { precision and consistency of underlying speech movements in the absence of } \\
\text { neuromuscular deficits. }\end{array}$ \\
\hline Expressive Aphasia & $\begin{array}{l}\text { A communication disorder characterized by use of predominantly single works, } \\
\text { short/fragmented phrases, incorrect syntax, jargon, etc. }\end{array}$ \\
\hline Fluent Aphasia & $\begin{array}{l}\text { A communication disorder characterized by fluent and meaningless speech and } \\
\text { difficulty understanding spoken speech (also known as Wernicke's aphasia). }\end{array}$ \\
\hline Global Aphasia & $\begin{array}{l}\text { A communication disorder characterized by difficulty with both expressive and } \\
\text { receptive language. }\end{array}$ \\
\hline Left Cerebrovascular Accident (LCVA) & $\begin{array}{l}\text { Damage to the left side of the brain that result in difficulty speaking and understanding } \\
\text { language. }\end{array}$ \\
\hline Non-fluent Aphasia & $\begin{array}{l}\text { A communication disorder (known as Broca's aphasia) characterized by expressive } \\
\text { language deficits and difficulty producing lengthy, complete and syntactically correct } \\
\text { phrases and sentences. }\end{array}$ \\
\hline Paraphasia & $\begin{array}{l}\text { A feature of aphasia where an individual often substitutes one word for another, and/or } \\
\text { adjusts word meaning. }\end{array}$ \\
\hline Post-onset & A term used to describe a period after the initiation of an event or incidence. \\
\hline Receptive Aphasia & $\begin{array}{l}\text { A communication disorder characterized by difficulty understanding spoken messages, } \\
\text { an increased rate of speech, and language subtleties (such as humor and figurative } \\
\text { speech). }\end{array}$ \\
\hline Right Cerebrovascular Accident (RCVA) & $\begin{array}{l}\text { Damage to the ride side of the brain that results in challenges with attention, } \\
\text { recognition, vision, hearing, and body awareness in space. }\end{array}$ \\
\hline Stroke & $\begin{array}{l}\text { The sudden death of brain cells in a specific area due to inadequate or excessive blood } \\
\text { flow. }\end{array}$ \\
\hline Traumatic Brain Injury (TBI) & An injury to the brain resulting from an external force. \\
\hline
\end{tabular}

* Information for the definitions was collected from ASHA.org, Google and Wikipedia. 


\section{Appendix D: Definition Research Designs}

\begin{tabular}{|c|c|}
\hline Term & Definition \\
\hline$A-B$ & $\begin{array}{l}\text { A two-part or two-phase design composed of a baseline ("A" phase) with no changes, } \\
\text { and a treatment/intervention phase ("B" phase) in which and intervention or treatment is } \\
\text { implemented. }\end{array}$ \\
\hline A-B-A & $\begin{array}{l}\text { Known as a reversal design in which there is a baseline phase ("A"), a treatment phase } \\
\text { (" } B \text { "), and then a return to the baseline condition. }\end{array}$ \\
\hline Alternating Treatment & $\begin{array}{l}\text { A design used to compare two treatments by alternating each treatment in quick } \\
\text { succession. }\end{array}$ \\
\hline Case Study & A detailed analysis and/or intensive study of a person or a group. \\
\hline Double Cross-over & $\begin{array}{l}\text { An investigation conducted over time in which participants receive a sequence of } \\
\text { different treatments. }\end{array}$ \\
\hline Multiple-Baseline & $\begin{array}{l}\text { A research design that assesses changes across participants and/or settings through } \\
\text { staggered implementation of particular variables. }\end{array}$ \\
\hline Pre-/Post & Administration of a tools and/or assessment before and after a particular time. \\
\hline Randomized & A sampling technique that selects items at random without any predictable pattern. \\
\hline Randomized Control Trial (RCT) & $\begin{array}{l}\text { Considered the "gold standard" for scientific experimentation, this technique ensures } \\
\text { that participant grouping is randomly assigned. }\end{array}$ \\
\hline Single-subject & $\begin{array}{l}\text { A research design in which the participant serves as his or her own control, rather than } \\
\text { using a group of participants as the comparison group. }\end{array}$ \\
\hline
\end{tabular}

* Information for the definitions was collected from ASHA.org, Google and Wikipedia.

\section{Appendix E: Description of Tests and Interventions Used}

\begin{tabular}{|l|l|}
\hline Term & Definition \\
\hline Auditory Comprehension & The ability to understand spoken language. \\
\hline $\begin{array}{l}\text { Boston Diagnostic Aphasia } \\
\text { Examination (DBAE) }\end{array}$ & $\begin{array}{l}\text { A test used to evaluate adults suspected of having aphasia. It evaluates language skills } \\
\text { based on perceptual modalities, processing functions, and response modalities. }\end{array}$ \\
\hline Boston Naming Test & $\begin{array}{l}\text { A neuropsychological assessment used to measure confrontational word retrieval in } \\
\text { individuals with aphasia or other language disturbances. }\end{array}$ \\
\hline Motor Learning Guided (MLG) & $\begin{array}{l}\text { A theory of motor learning involving the limbs, which emphasizes practice to achieve a } \\
\text { desired movement outcome. }\end{array}$ \\
\hline Script & $\begin{array}{l}\text { Training that facilitates verbal communication on client-selected topics through } \\
\text { repetition. }\end{array}$ \\
\hline Speech Generating Device (SGD) & $\begin{array}{l}\text { A voice output communication device used to supplement or replace existing speech } \\
\text { for individuals with complex communication needs. }\end{array}$ \\
\hline Story Retell Procedure (SRP) & $\begin{array}{l}\text { A preferred method for assessing connected language that details important linguistic } \\
\text { characteristics or story retelling. }\end{array}$ \\
\hline
\end{tabular}

* Information for the definitions was collected from ASHA.org, Google and Wikipedia. 
